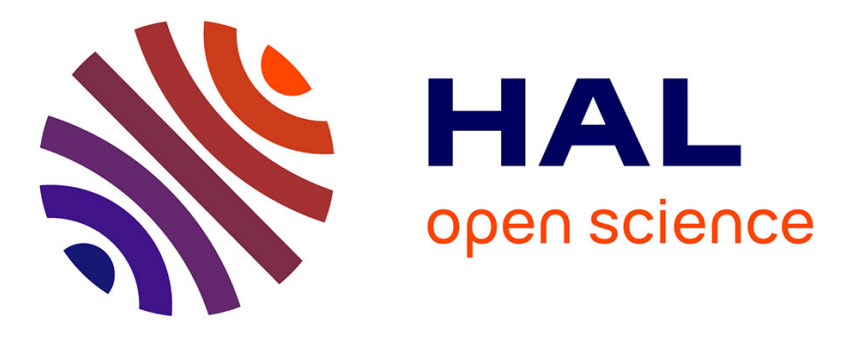

\title{
Multipath study on the airport surface
}

Audrey Guilloton, Jean-Pierre Arethens, Anne-Christine Escher, Christophe Macabiau, Damien Koenig

\section{To cite this version:}

Audrey Guilloton, Jean-Pierre Arethens, Anne-Christine Escher, Christophe Macabiau, Damien Koenig. Multipath study on the airport surface. IEEE/ION PLANS 2012, Position Location and Navigation System Conference, Apr 2012, Myrtle Beach, United States. pp.355-365, 10.1109/PLANS.2012.6236902 . hal-01022316

\section{HAL Id: hal-01022316 https://hal-enac.archives-ouvertes.fr/hal-01022316}

Submitted on 31 Oct 2014

HAL is a multi-disciplinary open access archive for the deposit and dissemination of scientific research documents, whether they are published or not. The documents may come from teaching and research institutions in France or abroad, or from public or private research centers.
L'archive ouverte pluridisciplinaire HAL, est destinée au dépôt et à la diffusion de documents scientifiques de niveau recherche, publiés ou non, émanant des établissements d'enseignement et de recherche français ou étrangers, des laboratoires publics ou privés. 


\section{Multipath Study On The Airport Surface}

\author{
Audrey GUILLOTON \\ Jean-Pierre ARETHENS \\ THALES AVIONICS \\ France
}

\author{
Anne-Christine ESCHER \\ Christophe MACABIAU \\ ENAC \\ France
}

\author{
Damien KOENIG \\ GIPSA-LAB \\ France
}

\begin{abstract}
Airport Navigation will require more stringent localization performance requirements than in-flight navigation [1]. GNSS signals (Global Navigation Satellites Systems) can be envisaged to elaborate the aircraft estimate position on the airport surface. To improve the performance of localization on the airport, the errors on GNSS signals particular to the airport environment must be characterized. Most of these errors are well known such as ionosphere error, troposphere error, etc, and do not depend on the airport environment. But to achieve the expected sub-metric performance, it is necessary to better model multipath error for which a model already exists but is valid for operations from en-route down to CAT I only.
\end{abstract}

In this paper, an analysis of real GPS measurements (using code pseudorange measurement, carrier phase measurement, Doppler measurement and the estimate $\mathrm{C} / \mathrm{NO}$ ratio measurement) during taxiing operation on the airport surface is conducted.

The goal of this paper is to evaluate when multipath occurs and to compare the multipath model (elaborated from the standard deviation of the measurement errors due to multipath) based on those collected measurements in the airport with different models proposed in the literature (not necessary proposed for airport navigation).

Keywords-component: Multipath, Airport Surface Movement

\section{INTRODUCTION}

In a recent ICAO (International Civil Aviation Organization) press release [2], a 5.1\% increase in the number of passengers has been assessed between 2010 and 2011. This increase implies more aircraft traffic on the airport surface. This general increase in airport traffic and the complexity of modern airport layouts have conducted to think about new technologies to assist pilots during maneuvers on airport surface.

Currently, a modern aircraft generally uses multi-sensor navigation system compliant with the requirements of the different area navigation operations defined in the ICAO PBN (Performance Based Navigation) manual [3], for in-flight navigation. It is intended that these navigation means, such as GNSS and INS (Inertial Navigation System), will be the basis for the delivery of the position supporting airport navigation applications.
GNSS measurements are affected by errors, which degrade positioning. On the airport surface, one of the main contributors to measurement errors is the multipath error. Currently, only multipath model for in-flight conditions is valid. This paper introduces a multipath study on the airport surface.

To get our multipath model, we first identify the instants where there is multipath. To detect multipath in the measurements, the method proposed by Lee [4] is used. It is a statistical method based on the double difference computation of code and phase measurements on L1 between two consecutives instants.

In the time intervals when multipath is detected, we compute its magnitude using a Code-Minus-Carrier (CMC) method as described in [5]. This method based on the simple difference of code and phase measurements on L1 allows to eliminate common error terms in the measurements but the obtained CMC measurements do not only contain multipath error but also code tracking error. Multipath error and also thermal noise on code measurement are evaluated and analyzed according to the satellite elevation angle. Then, for each elevation angle value, standard deviation of the multipath plus noise error is estimated: this defines our multipath model. This model will be compared with different models available in the literature.

Indeed, multipath error for airport navigation is not defined in standards today. SARPs [6] provides a multipath residual error model valid for operation down to Cat I, not validated for ground applications. The validity of this model for Cat II and Cat III operation is assessed in [18]. A model for airport environment has been proposed in DO247 [7] where airborne standard deviation error bounds were determined for different surface movement but this standard has not been completely validated or promulgated. More recently, the Working Group C [8] proposes three models: the open sky model, the suburban model and the urban model. Besides, these models are provided for several generic non-aviation use cases. In this paper, we compare these three models with real multipath measurements in order to select a model for airport navigation.

The organization of the paper is the following. The first section reminds the model of GPS code-pseudorange and carrier phase measurements. The next section describes the 
method to detect multipath. The third part introduces the method to estimate the multipath. Then, this estimation is statistically analyzed to be compared with the three models, and to see which model seems to be appropriate for airport navigation.

\section{MODEL OF GPS CODE-PSEUDORANGE AND CARRIER PHASE MEASUREMENTS}

Global Navigation Satellite Systems (GNSS) are global coverage satellite systems that provide position, velocity and time (PVT) services and provide a certain performance level in terms of accuracy, availability, continuity and integrity. The satellite-based element is composed of three distinct parts, also called segments: the space segment, the control segment and the user segment. In the future it is planned that there will be several constellation providing signals on several frequencies available for civil aviation. Currently, only GPS L1 is used.

GNSS positioning is based on trilateration. A user needs to track four satellite signals from the same constellation to determine position. The pseudorange, between satellite and receiver, may be obtained using two types of measurements: either code or carrier phase measurement.

Every GPS single frequency measurement (pseudorange, phase, Doppler) is affected by a number of errors.

The main contribution is due to propagation phenomena. GPS signals cross the atmosphere which is divided into several layers, and which affect the signal propagation.

In flight, ionosphere is the main source of raw GPS errors for an airborne receiver. Then follows troposphere and multipath [9][10]. Corrections of these errors are necessary to achieve a precise aircraft positioning.

Ionosphere error can be eliminated using dual frequency measurements. If a single frequency receiver is used, error models such as the Klobuchar model can be used [11]. Troposphere delay can nowadays be accurately modeled.

On ground, signal masking caused by buildings and natural obstructions, and multipath can also deteriorate GPS signal. The impact of these effects can result in loss of signal tracking (partially or totally) or/and tracking error. Tracking errors can result in position errors. Multipath is the largest contributor on pseudorange error on airport surface [12][13]. In our case, it is principally due to buildings and surrounding traffic [12][13].

To see how each measurement is affected by errors, code pseudorange measurement model and carrier phase measurement model are detailed in next sections.

\section{A. Code-pseudorange measurement model}

Each satellite transmits a pseudo-random code. Receiver generates locally the same pseudo-random code. Measurement of propagation time delay is the difference between code transmitted and code received.

The acknowledgment of the pseudo-random code permits to obtain the measurement of code pseudorange. The code generated by the satellite, arrives at the receiver antenna with a delay $\Delta t$ that corresponds to the time delay of the wave propagation (time to travel the path satellite-receiver).

The code pseudorange measurement between the receiver and the $\mathrm{j}^{\text {th }}$ satellite at the $\mathrm{i}^{\text {th }}$ epoch is modeled by:

$$
\tilde{\rho}_{i}^{j}=\rho_{i}^{j}+c\left(d t_{S}-d t_{R}\right)+E_{i}^{j}+I_{i}^{j}+T_{i}^{j}+M_{i}^{j}+W_{i}^{j}
$$

where

$\begin{array}{ll}\rho_{i}^{j} & \text { is the true distance } \\ c\left(d t_{S}-d t_{R}\right) & \text { is the satellite and receiver clock error } \\ E_{i}^{j} & \text { is the ephemeris error } \\ I_{i}^{j} & \text { is the ionospheric error } \\ T_{i}^{j} & \text { is the troposheric error } \\ M_{i}^{j} & \text { is the multipath error } \\ W_{i}^{j} & \text { is the thermal noise error with } W_{i}^{j} \sim\left(0, r_{\rho}\right)\end{array}$

\section{B. Carrier phase measurement model}

From carrier of GPS signal (L1 or L2), it is theoretical possible to obtain a measurement of the distance between receiver and satellite.

Range $\rho_{i}^{j}$ between satellite $j$ and receiver at the $\mathrm{i}^{\text {th }}$ epoch is obtained by comparing signal carrier at reception time with carrier at transmission time.

The carrier phase measurement is modeled by:

$$
\begin{aligned}
\widetilde{\Phi}_{i}^{j}= & \rho_{i}^{j}+c\left(d t_{S}-d t_{R}\right)+E_{i}^{j}-I_{i}^{j}+T_{i}^{j} \\
& +m_{i}^{j}+w_{i}^{j}+\lambda N_{i}^{j}
\end{aligned}
$$

where

$m_{i}^{j} \quad$ is the carrier-phase multipath error

$w_{i}^{j} \quad$ is thermal noise error with $w_{i}^{j} \sim\left(0, r_{\phi}\right)$

$N_{i}^{j}$ is the unknown integer ambiguity

\section{METHOD TO DETECT MULTIPATH}

This section will describe the method employed to detect multipath in measurements.

\section{A. Available measurements}

Multipath is extracted from pseudorange measurement to be characterized. Results introduced in this paper are issued of the analysis of 160 flight recordings. Measurements were collected with ASHTECH Z12 dual-frequencies L1/L2 receiver used for trajectography purpose during flight tests. The antenna is a specific trajectography antenna which is distinct from operational aviation antenna.

In each recording, the available measurements are: 
- Code-pseudorange measurements on L1 and L2 (C/A code and P code measurements)

- $\quad$ Phase measurements on L1 and L2

- Doppler measurements on L1 and L2

- $\mathrm{C} / \mathrm{N} 0$ on L1 and L2

First, the taxiing phases are identified in each recording thanks to the altitude of the aircraft. Figure 1 depicts the altitude as a function of the GPS time.

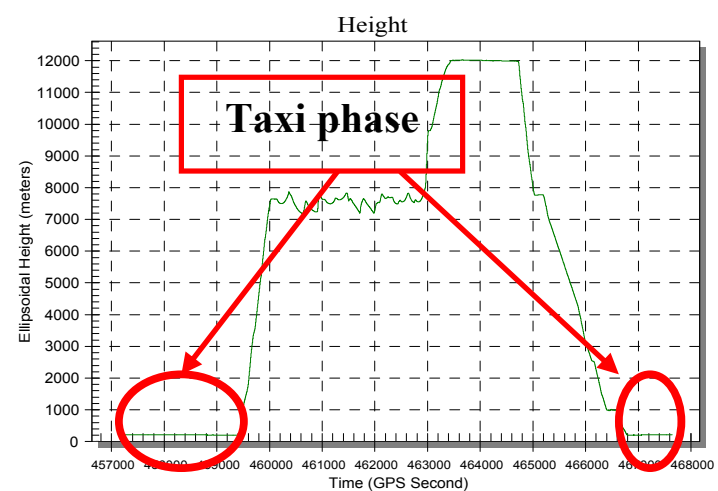

Figure 1: Aircraft altitude

Then, multipath is detected during the taxing phases using the method proposed by Lee [4].

\section{B. Method to detect presence of multipath}

To detect multipath in the measurement, the method described in [4] is used. It is a statistical method based on the double difference computation of code and phase measurements on L1 between two consecutive instants.

Let $\widetilde{\rho}_{i}^{j}$ and $\widetilde{\Phi}_{i}^{j}$ be the code and phase measurements respectively, of the $\mathrm{j}^{\text {th }}$ satellite at the $\mathrm{i}^{\text {th }}$ epoch. The residual error $\left(d_{i}^{j}\right)$ of this double difference, also called STDD (Successive-Time Double-Differences) in [4] can be written as (using the same notation as previously):

$$
d_{i}^{j}=\left(\widetilde{\rho}_{i}^{j}-\widetilde{\rho}_{i-1}^{j}\right)-\left(\widetilde{\Phi}_{i}^{j}-\widetilde{\Phi}_{i-1}^{j}\right)=\mu_{i}^{j}+v_{i}^{j}
$$

Where

$$
\begin{aligned}
\mu_{i}^{j}= & \left(M_{i}^{j}-M_{i-1}^{j}\right)-\left(m_{i}^{j}-m_{i-1}^{j}\right) \\
& +2\left(I_{i}^{j}-I_{i-1}^{j}\right)-\lambda\left(N_{i}^{j}-N_{i-1}^{j}\right) \\
v_{i}^{j}= & \left(W_{i}^{j}-W_{i-1}^{j}\right)-\left(w_{i}^{j}-w_{i-1}^{j}\right)
\end{aligned}
$$

with

$$
\begin{aligned}
\left(\begin{array}{c}
v_{i}^{j} \\
v_{l}^{j}
\end{array}\right) & \sim\left(\left[\begin{array}{l}
0 \\
0
\end{array}\right], \quad\left[\begin{array}{cc}
\Lambda_{\rho} & \frac{-1}{2} \Lambda_{\rho} \\
\frac{-1}{2} \Lambda_{\rho} & \Lambda_{\rho}
\end{array}\right]\right) \quad \text { if } l=i \pm 1 \\
& \sim\left(\left[\begin{array}{l}
0 \\
0
\end{array}\right], \quad\left[\begin{array}{cc}
\Lambda_{\rho} & 0 \\
0 & \Lambda_{\rho}
\end{array}\right]\right) \text { if } l \neq i \pm 1 \\
\Lambda_{\rho}=2\left(r_{\rho}^{2}+r_{\phi}^{2}\right) &
\end{aligned}
$$

First, we neglect the rare cases of ionospheric scintillation. Thus we may assume $2\left(I_{i}^{j}-I_{i-1}^{j}\right)$ is negligible. Since the distance traveled by the receiver between 2 consecutive epochs is very short.

It is assumed that no cycle slips occurs and no data is lost between two consecutive instants so the term $\lambda\left(N_{i}^{j}-N_{i-1}^{j}\right)$ is negligible. So the term $\mu_{i}^{j}$ can be simplified as:

$$
\mu_{i}^{j}=\left(M_{i}^{j}-M_{i-1}^{j}\right)-\left(m_{i}^{j}-m_{i-1}^{j}\right)
$$

Thus when multipath does not affect signals, the term $v_{i}^{j}$ which stands for tracking errors - is the dominant term in $d_{i}^{j}$. When multipath affects signals, there is incoherence between code-phase and carrier-phase, principally due to the discriminator code bias. Hence, the term $\mu_{i}^{j}$ is not any more negligible with respect to the noise and permits to detect multipath.

\section{1) Hypothesis test definition}

From the STDD previously elaborated, a statistic test can be computed with an iterative process, for each satellite.

The subsequent $d_{i}^{j}$ and $d_{i+1}^{j}$ are correlated as shown in previously equation. It is necessary to decorrelate the STDD sequence. To do this, a stochastic orthogonalization is applied to $d_{i}^{j}$ from the $(k-B+1)^{t h}$ epoch to the $k^{t h}$ epoch:

$$
\begin{gathered}
\bar{\Lambda}_{i}^{j}=\Lambda_{i}^{j}-\frac{1}{4} \frac{\Lambda_{\rho}}{\bar{\Lambda}_{i-1}^{j}}, \quad \bar{\Lambda}_{k-B+1}^{j}=\Lambda_{\rho}, \forall i \in[k-B+1 ; k] \\
\bar{d}_{i}^{j}=d_{i}^{j}+\frac{1}{2} \frac{\Lambda_{\rho}}{\Lambda_{i-1}^{j}} \bar{d}_{i-1,}^{j}, \quad \bar{d}_{k-B+1}^{j}=d_{k-B+1}^{j}
\end{gathered}
$$

The orthogonalized sequence $\bar{d}_{i}^{j}$ is independent Gaussian in normal signal conditions:

$$
\left[\begin{array}{c}
\bar{d}_{k}^{j} \\
\bar{d}_{k-1}^{j} \\
\vdots \\
\bar{d}_{k-B+1}^{j}
\end{array}\right] \sim\left(\left[\begin{array}{c}
0 \\
0 \\
\vdots \\
0
\end{array}\right],\left[\begin{array}{cccc}
\Lambda_{k}^{j} & 0 & \cdots & 0 \\
0 & \Lambda_{k-1}^{j} & \ddots & \vdots \\
\vdots & \ddots & \ddots & 0 \\
0 & \ldots & 0 & \Lambda_{k-B+1}^{j}
\end{array}\right]\right)
$$


A test statistic to detect abnormal signal condition can be applied since $\bar{d}_{i}^{j}$ is decorrelated:

$$
T_{k-B+1 / k}^{j}=\sum_{k-B+1}^{k} \frac{\left(\bar{d}_{i}^{j}\right)^{2}}{\bar{\Lambda}_{i}^{j}}=T_{k-B+1 / k-1}^{j}+\frac{\left(\bar{d}_{k}^{j}\right)^{2}}{\bar{\Lambda}_{k}^{j}}
$$

More details on this statistic test can be found in [4].

Multipath is detected thanks to a binary Neyman Pearson test with a test variable following a $\chi^{2}$ distribution.

The decision rule of the $\chi^{2}$ test is:

If $T_{k-B+1 / k}^{j} \leq T_{\text {thres }},\left(H_{0}\right)$ is assumed, it means that multipath does not affect GPS signals.

If $T_{k-B+1 / k}^{j} \geq T_{\text {thres }},\left(H_{1}\right)$ is assumed, it means that multipath affects GPS signals.

The test is designed such as it allows to detect strong magnitude errors (with distribution different from that of a Gaussian noise).

Figure 2 and 3 illustrate representative examples of the test statistic evolution as a function of the time and of the detection threshold value. Figure 2 illustrates a signal affected by multipath (when statistic test is over the threshold depicted in red) and figure 3 illustrates a signal which is not affected by multipath.

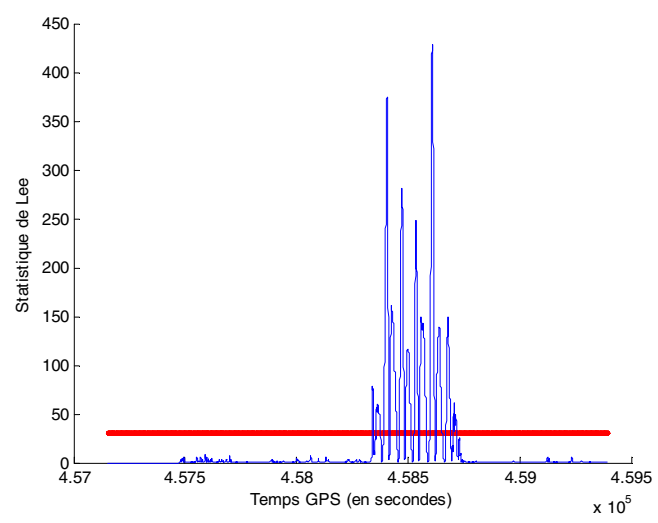

Figure 2: Statistic test of a signal affected by multipath

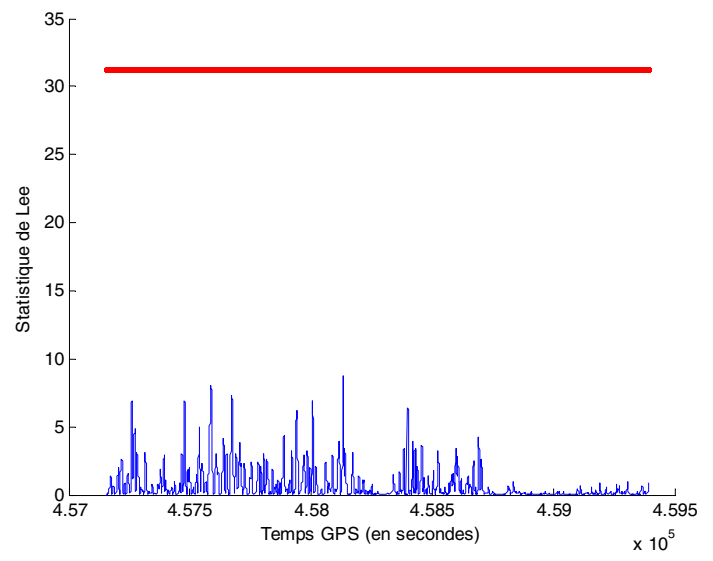

Figure 3: Statistic test of a signal not affected by multipath

Multipath has been detected in 70 flight recordings among the 160 ones. 30 flight recordings have one or more significant multipath periods, similar to the example taken in this paper, whereas some flight recordings have no multipath detected. The next section highlights some factors contributing to multipath.

\section{Factors contributing to multipath}

The probability to have a multipath is higher when the aircraft moves on the apron or stands at the gate. First, it is due to the low speed of the aircraft in these phases operations and then due to the proximity of obstacles (building or other aircraft).

So when multipath is detected, we have verified where the aircraft was situated and also the aircraft speed.

To identify in which zone was the aircraft (runway, taxiway, apron or gate [1]) trajectories have been depicted with Google Earth (®). In all the flight recordings, aircraft was closed to buildings when multipath was detected. Figure 4 depicts the place where the most numerous of multipath was detected. 


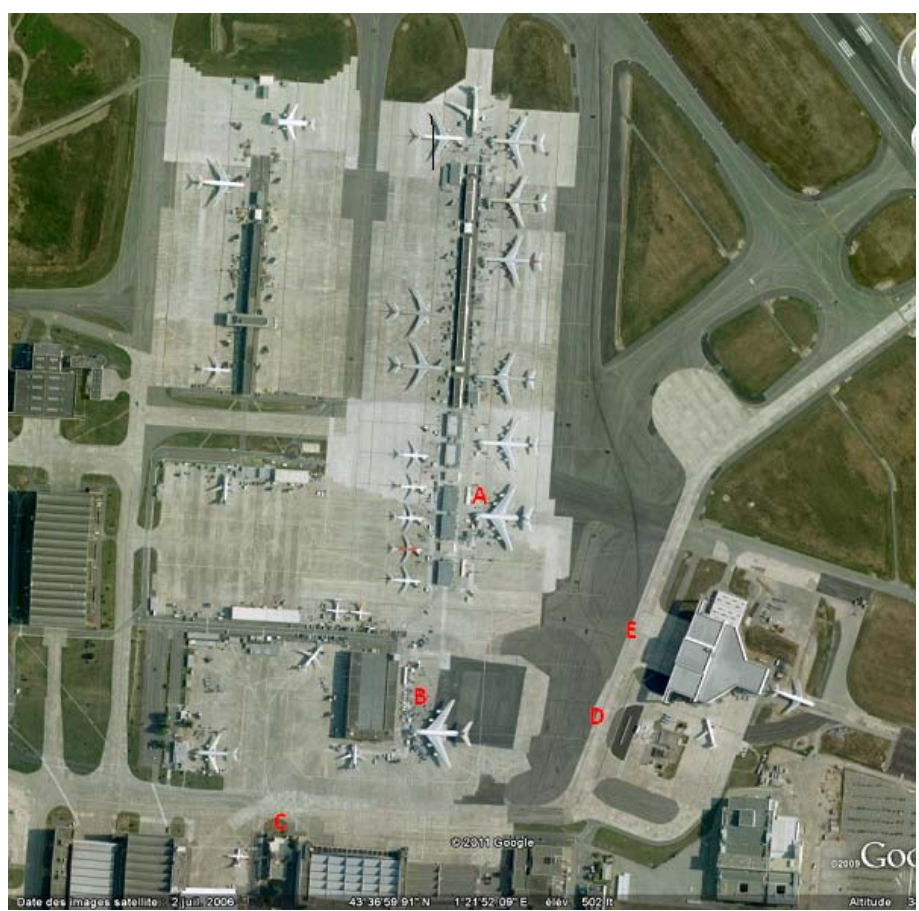

Figure 4: Obstacles proximity

It can be noted that no multipath was found on runway, high speed taxiway and taxiway for the retained threshold. Multipath is present at the gate (see letters A, B and C in figure 4) and on the apron (letters D and E).

During all the time intervals where multipath is detected, the aircraft speed is either null or very low as depicted in figure 5 .

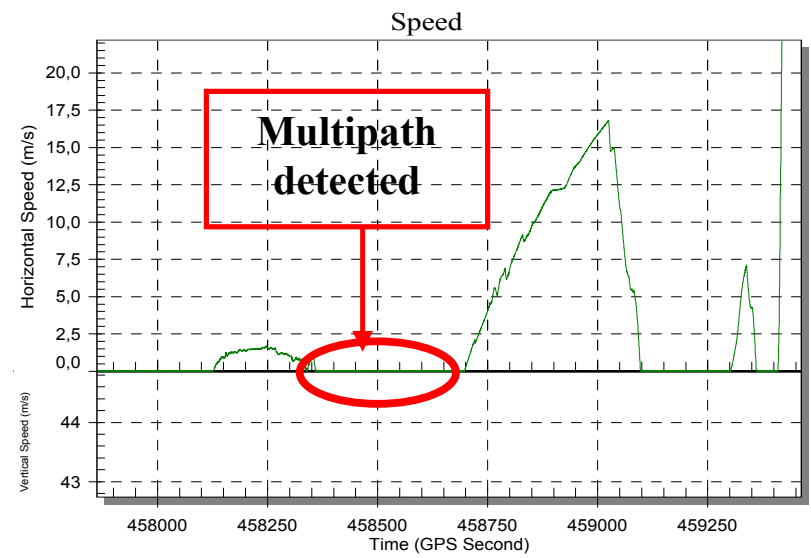

Figure 5: Aircraft speed

Aircraft on the airport surface is more sensitive to multipath when it is stopped or it moves with low speed, close to a building. No multipath was found when the velocity was not null.

Once multipath has been detected, error introduced by multipath on pseudo-distance is estimated.

\section{Method to estimate MULTIPATH}

To extract multipath from the code $\mathrm{C} / \mathrm{A}$ pseudorange measurement, it is necessary to eliminate other errors. The employed method is derived from the Braash method [5].

\section{A. Method proposed by Braasch}

The method is based on the simple difference of code and phase measurements on L1 C/A. The commonly error terms of measurements are thus eliminated.

The difference for one satellite $\mathrm{j}$ is expressed as:

$$
\tilde{\rho}^{j}-\tilde{\Phi}^{j}=2 I^{j}+M^{j}-m^{j}+W^{j}-w^{j}-\lambda N^{j}
$$

Dual frequency measurements are available in flight recordings so the ionospheric correction can be computed using the physical properties of the ionosphere. To estimate the ionospheric delay, code measurements on L1 and L2 are used.

Code pseudoranges on L1 and L2 can be written as:

$$
\begin{gathered}
{\tilde{\rho_{i}{ }_{L 1}}}^{j}=\rho_{i}^{j}+I_{i L 1}^{j}+\Sigma_{i}^{j} \\
{\tilde{\rho_{i L 2}^{j}}}^{j}=\rho_{i}^{j}+I_{i L 2}^{j}+\Sigma_{i}^{j}
\end{gathered}
$$

where

$\rho_{i}^{j} \quad$ represents the true distance

$I_{i L 1}^{j} \quad$ represents the ionospheric delay on $\mathrm{L} 1$

$I_{i L 2}^{j} \quad$ represents the ionospheric delay on $\mathrm{L} 2$

$\Sigma_{i}^{j} \quad$ represents the common error on L1 and L2 (tropospheric error, ephemeris error ...): $\Sigma_{i}^{j}=c\left(d t_{S}-d t_{R}\right)+E_{i}^{j}+T_{i}^{j}$. Errors link to receiver inter-frequency on L1 and L2 are considered constant and are also neglected.

The electronic density is the same for L1 and L2 [5], so:

$$
I_{L 1}=\frac{A}{f_{1}^{2}} \text { and } I_{L 2}=\frac{A}{f_{2}^{2}}
$$

where $\mathrm{A}$ is the ionospheric coefficient

So, we get:

$$
I_{L 2}=\frac{f_{1}^{2}}{f_{2}^{2}} I_{L 1}
$$

After doing the pseudorange difference, we obtain the ionospheric delay:

$$
I_{L 1}=\frac{f_{2}^{2}}{f_{2}^{2}-f_{1}^{2}}\left(\tilde{\rho}_{L 1}-\tilde{\rho}_{L 2}\right)
$$


Once the ionospheric delay subtracted, we get:

$$
\tilde{\rho}^{j}-\tilde{\Phi}^{j}=M^{j}+W^{j}-\lambda N^{j}-m^{j}-w^{j}
$$

Integrated Doppler multipath and noise errors (about some millimeters) may be neglected since code-multipath errors are typically of the orders of meters [5]. So we get:

$$
\tilde{\rho}^{j}-\tilde{\Phi}^{j}=M^{j}+W^{j}-\lambda N^{j}
$$

Now, the phase ambiguity must be removed. The mean of the difference (code-phase) allows to remove the continue component yield by the phase ambiguity.

$$
\tilde{\sim}^{j}-\tilde{\Phi}^{j}-\operatorname{mean}\left(\tilde{\rho}^{j}-\tilde{\Phi}^{j}\right)=M^{j}+W_{\text {smooth }}^{j}
$$

where

$$
W_{\text {smooth }}^{j} \quad \text { represents the noise after smoothing }
$$

Thermal noise on code measurement and multipath variable component constitute the residual error. Thermal noise is generally reduced by a code-carrier smoothing. It cannot be the case here, otherwise the high frequency component of multipath is not taken into account.

The residual error on the $\mathrm{C} / \mathrm{A}$ code measurement on L1 affected by a multipath is depicted in figure 6 . The observed significant oscillations represent the movement between direct and reflective waves. These oscillations can also be seen on the L1 C/N0 estimate as depicted in figure 7.

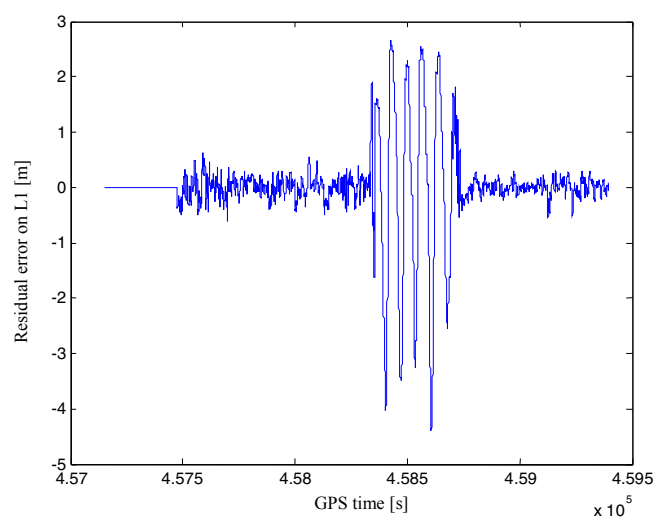

Figure 6: Residual error

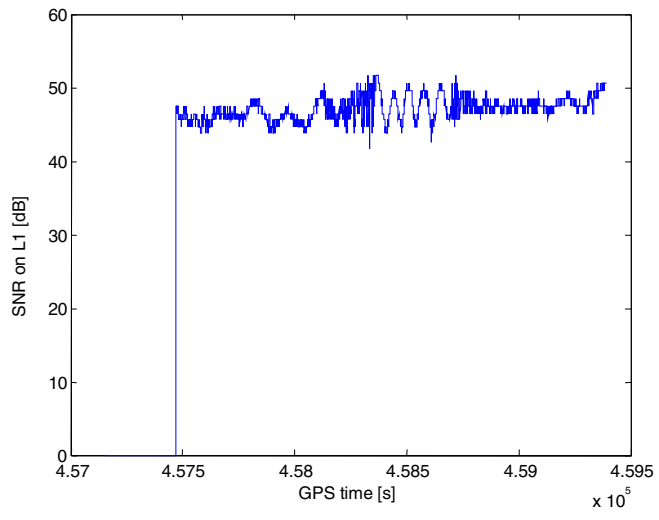

Figure 7: C/NO on L1

Multipath affects signals received from the satellite with amplitude of roughly $4 \mathrm{~m}$. The maximum amplitude of the multipath detected can reach about $10 \mathrm{~m}$.

To determine which model seems to be the most appropriate for airport navigation, a statistical analysis of those strong multipath estimates is done.

The result of this analyze is sum up in the next table:

\begin{tabular}{|c|c|c|c|}
\hline $\begin{array}{c}\text { Satellite } \\
\text { Elevation } \\
\text { Angle }\end{array}$ & STD & $\begin{array}{c}\text { Number of } \\
\text { points }\end{array}$ & $\begin{array}{c}\text { Number of } \\
\text { affected } \\
\text { satellites }\end{array}$ \\
\hline $5-10^{\circ}$ & 1,13 & 15172 & 8 \\
\hline $10-15^{\circ}$ & 2,47 & 7057 & 11 \\
\hline $15-20^{\circ}$ & 0,85 & 22873 & 13 \\
\hline $20-25^{\circ}$ & 0,72 & 7780 & 5 \\
\hline $25-30^{\circ}$ & 0,58 & 27150 & 10 \\
\hline $30-35^{\circ}$ & 1,09 & 11580 & 5 \\
\hline $35-40^{\circ}$ & - & - & \\
\hline $40-45^{\circ}$ & - & - & \\
\hline $45-50^{\circ}$ & 1,11 & 2496 & 1 \\
\hline $50-55^{\circ}$ & 1,82 & 4488 & 3 \\
\hline $55-60^{\circ}$ & - & - & \\
\hline $60-65^{\circ}$ & - & - & \\
\hline $65-70^{\circ}$ & 0,37 & 6738 & 3 \\
\hline $70-75^{\circ}$ & 1,72 & 8492 & 2 \\
\hline $75-80^{\circ}$ & - & - & \\
\hline $80-85^{\circ}$ & 0,71 & 1292 & 2 \\
\hline $85-90^{\circ}$ & - & - & \\
\hline
\end{tabular}

Table 1: Multipath + noise standard deviation

STD means standard deviation on the measurement errors due to multipath and noise. As we do not know the correlation that would be due to the receiver processing, we consider all the sample without taking into account the fact that they may be correlated. If that correlation were taken into account, the measurements should be processed differently. 
The symbol '-' denotes that no excessive multipath was detected on measurements of the satellites at that elevation angle in the flight recordings so no data were available to make a statistic.

The Multipath and Noise Measurement standard deviation (MNM) obtained without smoothing is then compared with models of the literature.

\section{STATISTICAL ANALYSIS OF MULTIPATH + NOISE ESTIMATES}

First, we introduce the multipath model currently used in civil aviation for operations from en-route down to Cat I. We remind this model is not valid on the ground. Another model elaborated by Working Group C [8] for urban and suburban environment is then described. The last model is the approach done by the RTCA [7] to characterize multipath on the airport surface.

Some model has been realized after smoothing whereas our model is given without smoothing. A factor is applied on model with smoothing to be compared. This factor, derived from [17], will be introduced.

\section{A. Multipath residual error according to SARPS}

The multipath error model proposed in [6] was developed and validated from flight test data, which were collected on large and fixed wing aircraft. More details can be found in [14].

The multipath residual error for the airborne equipment certified for flight is described by the distribution, $N\left(0, \sigma_{\text {multipath }}^{2}\right)$ where:

$$
\sigma_{\text {multipath }}=0.13+0.53 e^{(- \text {Elev } / 10 \mathrm{deg})} \text { (in meters) }
$$

where Elev is the elevation angle of satellite (in degrees).

Note: The multipath error sigma is valid down to 2 degrees and is applied after a code-carrier smoothing

Figure 8 shows the SARPs model of the multipath residual error standard deviation as a function of the satellite elevation.

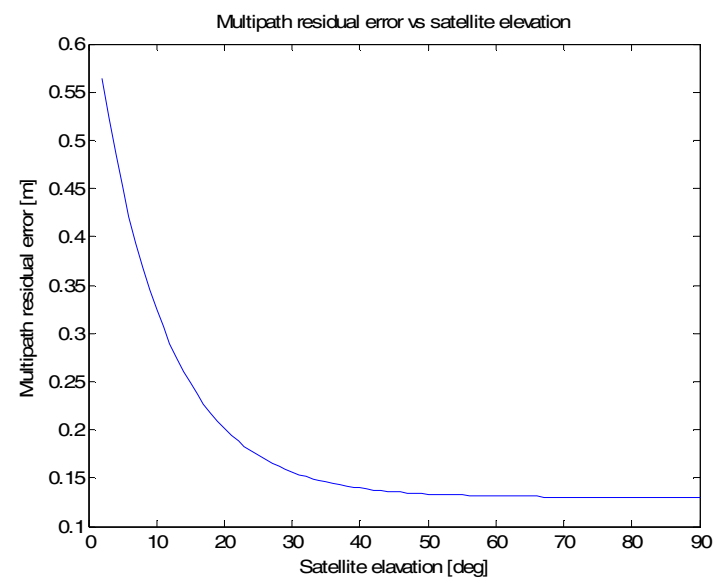

Figure 8: Multipath residual error vs satellite elevation as depicted in [6]
This multipath residual error is applicable to an aircraft in flight and not to an aircraft on the ground. This model cannot therefore be used to navigate on the airport surface.

\section{B. Multipath residual error according to Working Group C}

Working Group C proposes three models: the open sky model, the suburban model and the urban model. The open sky model cannot be considered here due to the proximity with obstacles (as buildings) on the airport surface. For the suburban case, a masking angle of 5 degrees elevation is considered (used by default in most of the receivers). In the urban model, a 15-degrees mask angle is retained. It is the minimum elevation at which the multipath model gives statistical information about the signals.

Urban multipath error standard deviation is described by Jahn's model for BOC(1,1), MBOC and BPSK(10) signals: :

$$
\sigma=\max \{a+b \cdot \arctan (c \cdot(\text { Elev }-d)), \varepsilon\}, \varepsilon=10^{-4}
$$

where

$\sigma$ is in meters,

Elev is the satellite elevation in degree.

The four parameters $(a, b, c, d)$ are shown in the next table:

\begin{tabular}{|c|c|c|c|}
\cline { 2 - 4 } \multicolumn{1}{c|}{} & BOC $(1,1)$ & MBOC & BPSK(10) \\
\hline$a$ & 6.3784 & 4.4144 & 2.0338 \\
\hline$b$ & -3.5782 & -2.871 & -1.3428 \\
\hline$c$ & 0.1725 & 0.1846 & 0.1462 \\
\hline$d$ & 29.075 & 27.6112 & 29.565 \\
\hline
\end{tabular}

Table 2: Model coefficients using Jahn's method - Urban (fitting with arc-tangent function) [8]

This formula was elaborated considering a non-coherent dot product discriminator with an early minus late correlator spacing of 0.1 chips.

Figure 9 below illustrates this model.

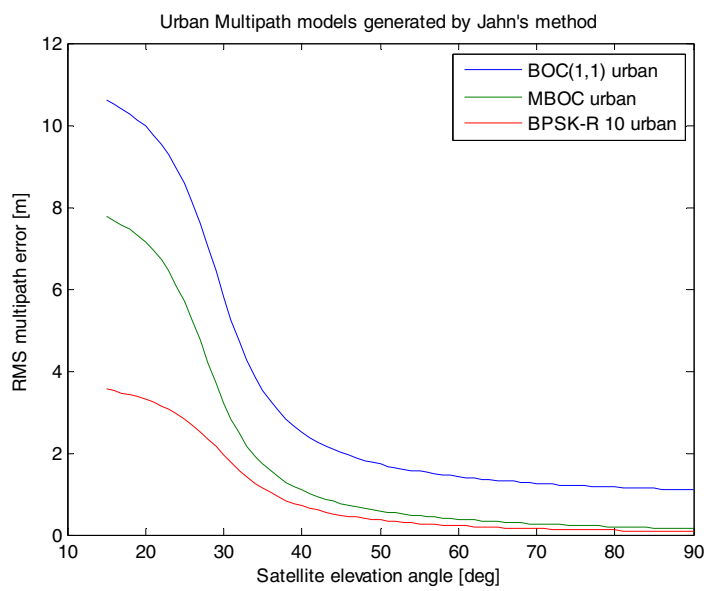

Figure 9: Urban Multipath models generated with Jahn's model 
These curves represent unsmoothed error such as our results. So Jahn's model can be directly compared with our results.

In suburban environments, the multipath error standard deviation using Jahn's model, also given without smoothing, is the following:

$$
\sigma=\max \{a+b \cdot \exp (c \cdot \text { Elev }), \varepsilon\}, \varepsilon=10^{-4}
$$

where

$\sigma$ is in meters,

Elev is the satellite elevation in degree.

The three parameters $(a, b, c)$ are shown in the next tables:

\begin{tabular}{|c|c|c|c|}
\cline { 2 - 4 } \multicolumn{1}{c|}{} & BOC $(1,1)$ & MBOC & BPSK(10) \\
\hline$a$ & 0.55349 & 0.14895 & 0.11211 \\
\hline$b$ & 30.254 & 2.5236 & 3.9561 \\
\hline$c$ & -0.23566 & -0.10811 & -0.13643 \\
\hline
\end{tabular}

Table 3: Model coefficients using Jahn's method Suburban (fitting with exponential function) [8]

It is depicted in figure 11.

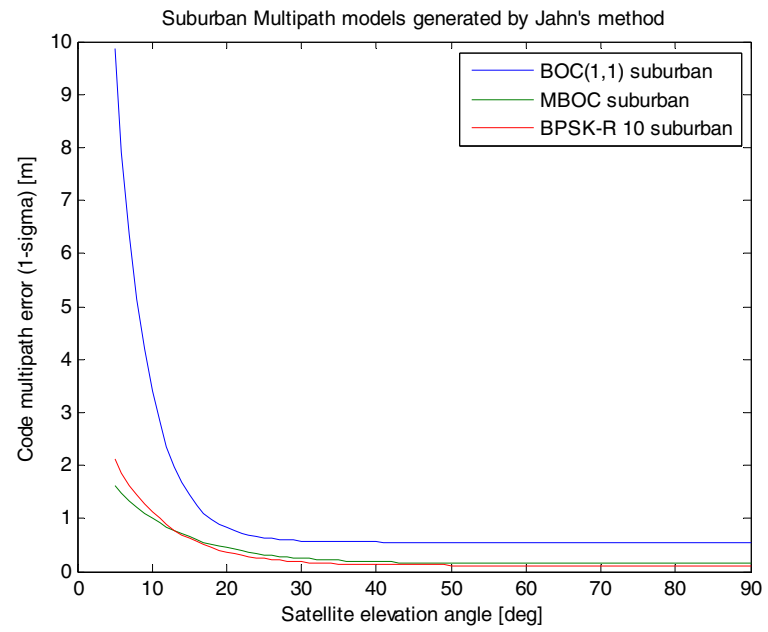

Figure 10: Suburban Multipath models generated by Jahn's method

Only red curves (for BPSK) are significant for our study because other relate to Galileo signals.

\section{Multipath residual error according to the DO247}

In order to derive a model for the aircraft uncorrelated GPS L1 C/A measurement error, both multipath and RFI (Radio Frequency Interference) effects on the airport surface as a function of operation were estimated using Monte-Carlo simulation techniques. With a multipath ray-tracing algorithm, airborne standard deviation error bounds were determined for each operational phase and the results are presented in [7]. It has to be noted that this result assumes that a GBAS augmentation is available. Two code-discriminators were envisaged as detailed in table 5.
Different aircraft receiver multipath and RFI environments are assumed. The error standard deviation as a function of satellite elevation angle $(\theta)$ after smoothing is given by:

\begin{tabular}{|c|c|c|}
\hline $\begin{array}{c}\text { Surface } \\
\text { Operation } \\
\text { /Scenario }\end{array}$ & $\begin{array}{c}\text { Worst case error } \\
\text { (meters) }\end{array}$ & $\begin{array}{c}\text { Best case error } \\
\text { (meters) }\end{array}$ \\
\hline $\begin{array}{c}\text { Scenario 1 / } \\
\text { Rapid exit }\end{array}$ & $0.21+0.175 \mathrm{e}^{-\theta / 12}$ & $0.105+0.137 \mathrm{e}^{-\theta / 12}$ \\
\hline $\begin{array}{c}\text { Scenario 2 / } \\
\text { Taxiway }\end{array}$ & $0.2+0.5237 \mathrm{e}^{-\theta / 20}$ & $0.1+0.4099 \mathrm{e}^{-\theta / 20}$ \\
\hline $\begin{array}{c}\text { Scenario 3 / } \\
\text { Taxilane }\end{array}$ & $0.2+0.712 \mathrm{e}^{-\theta / 25}$ & $0.1+0.558 \mathrm{e}^{-\theta / 25}$ \\
\hline $\begin{array}{c}\text { Scenario 4 / } \\
\text { Stand gate }\end{array}$ & $0.22+0.7904 \mathrm{e}^{-\theta / 23}$ & $0.11+0.6186 \mathrm{e}^{-\theta / 23}$ \\
\hline
\end{tabular}

\section{Table 4: Aircraft error model bounds for surface} operations [7]

The scenario 1 has to be employed when the aircraft is on the runway. The scenario 2 corresponds to the taxiway phase. The scenario 3 refers to the apron phase and the scenario 4 refers to the gate.

The worst-case and the best-case designators correspond to the receiver performance according to the code discriminator. These notations correspond to LAAS airborne accuracy designators $\mathrm{A}$ and $\mathrm{B}$, respectively [16]:

\begin{tabular}{|c|c|c|c|}
\hline $\begin{array}{c}\text { Accuracy } \\
\text { Designator }\end{array}$ & $\begin{array}{c}\text { Correlator } \\
\text { Spacing }\end{array}$ & $\begin{array}{c}\text { Implementation } \\
\text { Loss }\end{array}$ & $\begin{array}{c}\text { Airport } \\
\text { PseudoLites } \\
\text { induced } \\
\text { signal loss }\end{array}$ \\
\hline A & 1.0 chip & $2.5 \mathrm{~dB}$ & $0.6 \mathrm{~dB}$ \\
\hline B & 0.1 chip & $1.0 \mathrm{~dB}$ & $1.2 \mathrm{~dB}$ \\
\hline
\end{tabular}

Table 5: Assumptions for airborne accuracy designation

Figure 12 and 13 show the maximum aircraft error standard deviation (STD), after smoothing, as a function of satellite elevation angle considering the worst and the best case model respectively.

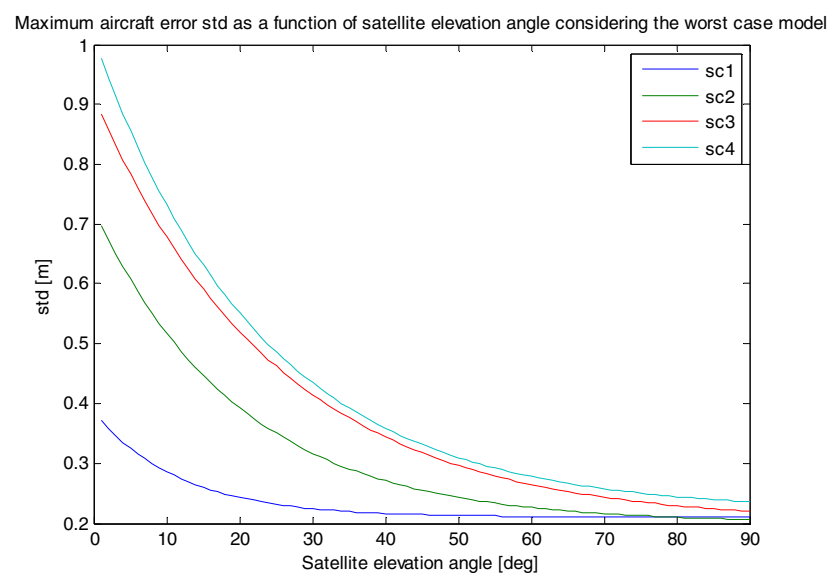

Figure 11: Maximum aircraft error STD as a function of satellite elevation angle considering the worst case model 


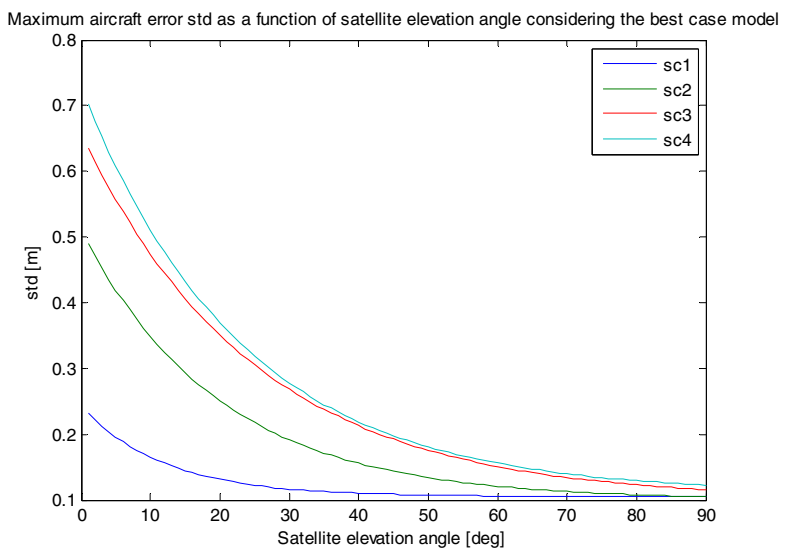

Figure 12: Maximum aircraft error STD as a function of satellite elevation angle considering the best case model

\section{Comparison between MNM and other models}

FAA and Boeing have presented their joint research about the effects of airborne and ground bounce multipath on GPS L1 C/A signals [17]. This paper introduces the Code-MinusCarrier smoothing effectiveness factor for GPS signals. It represents the ratio between the raw sigma and the smoothed sigma.

In our case, SARPs model and DO247 model are given assuming code-carrier smoothing. To be compared with Jahn urban and suburban models, the effectiveness factor is applied. This factor depends on the satellite elevation as depicted in figure 13 (a smoothing with a 100 seconds time constant is used to determine this factor). Factor considered in this paper are summarized in table 6 .

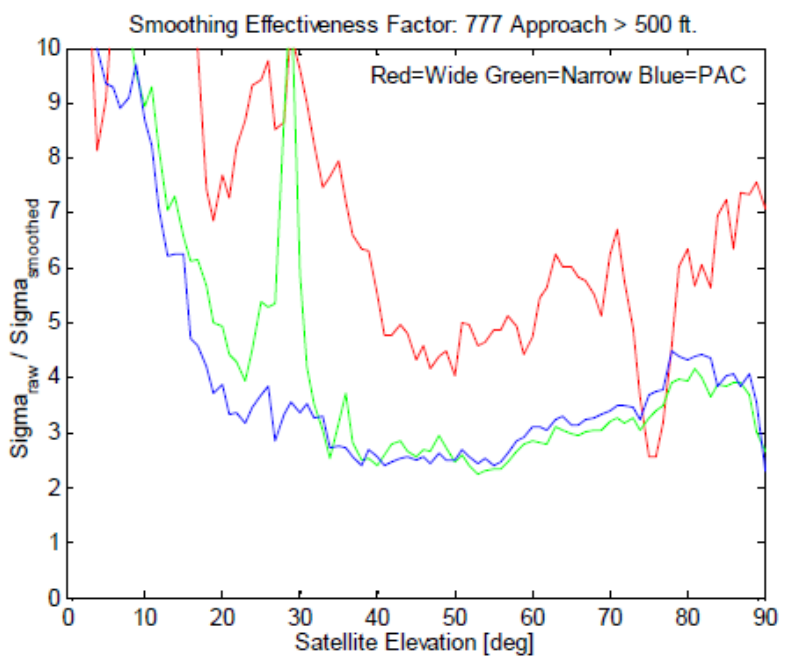

Figure 13: Code-Minus-Carrier Smoothing Effectiveness Factor - 777 on Approach > 500ft [17]

\begin{tabular}{|c|c|c|c|c|}
\hline $\begin{array}{c}\text { Satellite } \\
\text { Elevation }\end{array}$ & $0-10^{\circ}$ & $10-20^{\circ}$ & $20-30^{\circ}$ & $>30^{\circ}$ \\
\hline Factor & 10 & 7 & 4 & 3 \\
\hline
\end{tabular}

Table 6: Used Code-Minus-Carrier Smoothing Effectiveness Factor

Figure 14 depicts the MNM and also the SARPs model multiplied by the Code-Minus-Carrier Smoothing Effectiveness Factor. Figure 15 and 16 show the Jahn multipath model for the urban and suburban case respectively. Figure 17 represents the DO247 best-case model multiplied by the factor.

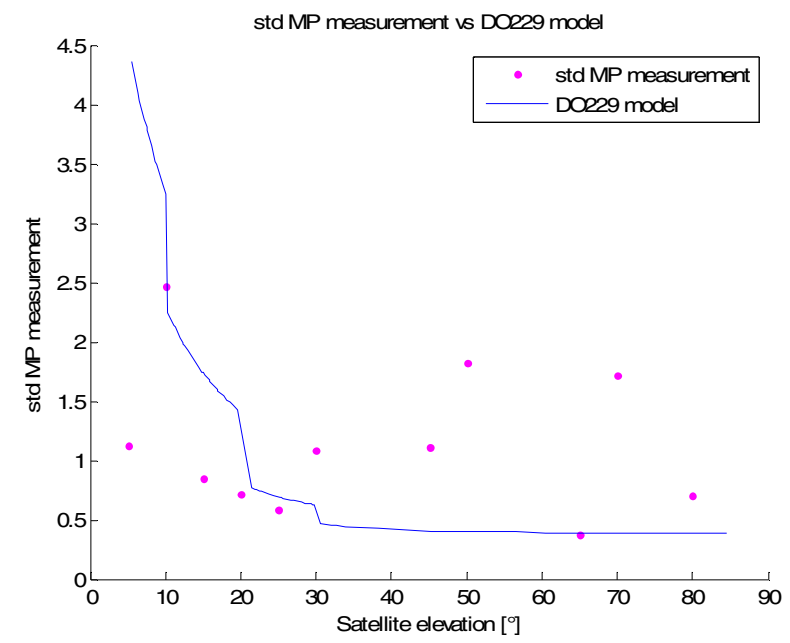

Figure 14: MNM vs SARPs model

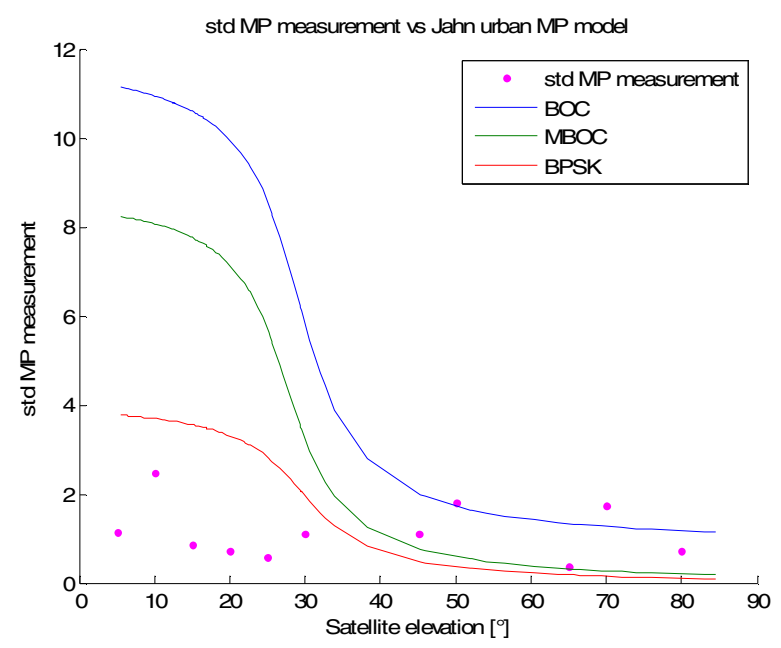

Figure 15: MNM vs Jahn urban multipath model (red curve for GPS) 


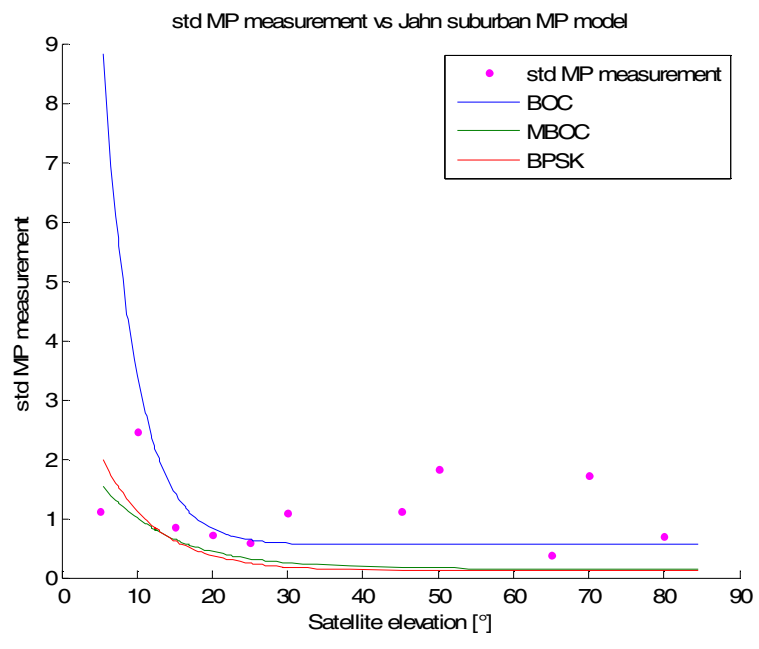

\section{Figure 16: MNM vs Jahn suburban multipath model (red} curve for GPS)

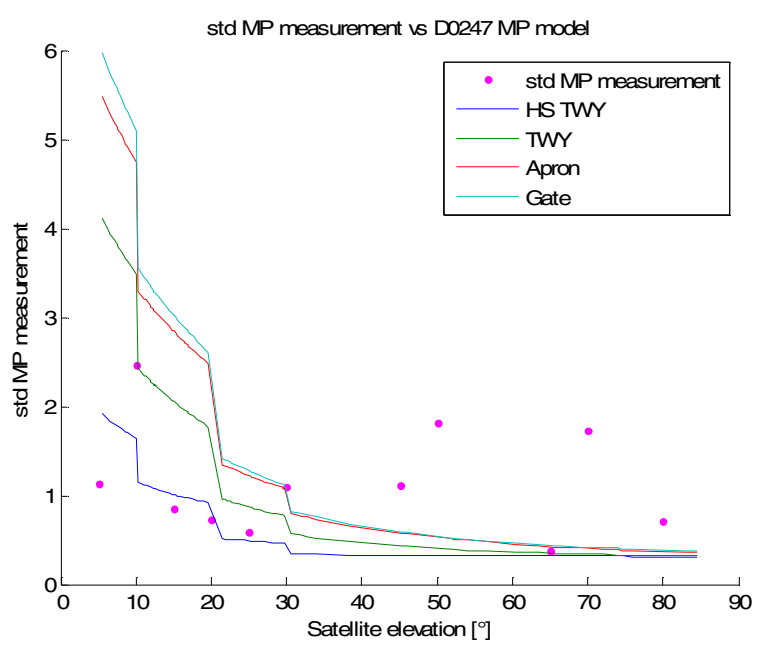

Figure 17: MNM vs DO247 best-case model

The number of points collected is not sufficient to determine a complete multipath model on the airport surface. For satellite elevation between $5^{\circ}$ and $35^{\circ}$, results obtained can be significant but for an elevation higher of $35^{\circ}$, the number of satellites affected is not sufficient. Results obtained are not representative above $35^{\circ}$ due to the poor satellite geometry variation.

It is not possible to conclude which is the most appropriate models due to the limited available data.

\section{CONCLUSION}

One of most contributors to pseudorange error on the airport surface is multipath. Standards define a model for inflight phases but it is not valid for taxiing operations. To improve applications for airport navigation, a multipath model on the airport surface is needed. This paper introduces a first approach based on the extraction of multipath error during taxiing.

The main conclusion of this paper is that no multipath is detected when the aircraft moves (the aircraft speed was not null). Multipath appears only when the aircraft is stopped at proximity of obstacles (buildings, ...). According to MNM extracted, it is difficult to conclude which model is the most appropriate for airport navigation. Only results obtained for satellite elevation lower $35^{\circ}$ can be significant.

Only strong multipath was considered in this study to estimate the multipath + noise standard deviation model. It can be noticed that even if measurements were non-code carrier smoothing measurement is applied, the standard deviation values are only of few meters and this even when the aircraft is close to the gate.

An improvement of this study could be to consider all the measurements and not only those affected by strong multipath.

\section{ACKNOWLEDGMENT}

The authors would like to thank Airbus for providing data used in this study.

The authors would also like to thank Carole Charlet, engineer student, for her help during the analysis of measurements.

\section{REFERENCES}

[1] A. Guilloton, JP. Arethens, C. Macabiau, AC. Escher, D. Koenig - A Methodology to Elaborate Aircraft Localization Requirements for Airport Navigation - ION GNSS conference, Portland - September 2011

[2] ICAO press release PIO 28/11, January 2012

[3] ICAO, "Performance Based Navigaion - Doc 9613", 2008

[4] H.K. Lee, J.G. Lee, G.I. Jee - GPS Multipath Detection Based on Sequence of Successive Time Double Differences - IEEE signal processing letters, vol. 11, no.3 - March 2004

[5] M. S. Braasch - Isolation of GPS Multipath and Receiver Tracking Errors, J. Institute of Navigation, vol. 41, pp. 511-521-1995

[6] ICAO, International Standards and Recommended Practices(SARPs), Annex 10 to the convention on international civil aviation, Aeronautical telecommunications, Volume 1 , radio Navigation Aids, $6^{\text {th }}$ edition July 2006, Amendment 85

[7] RTCA - The role of the global navigation satellite system (GNSS) in supporting airport surface operations - Final draft - Prepared by working group 4B, RTCA special committee 159 - DO247 - November $6^{\text {th }}, 1998$

[8] Working Group C - EU-US Cooperation on satellite navigation Combined performance for open GPS/Galileo receivers - Final version July $19^{\text {th }}, 2010$

[9] Department of Defense, "Global positioning system standard positioning performance standard", $4^{\text {th }}$ edition, September 2008

[10] Kaplan, "Understanding GPS principles and applications", 1996

[11] Parkinson and Spilker, "Global positioning system: theory and applications, volume I, volume 163 - Progess in astronautics and aeronautics", The American institute of aeronautics and astronautics, 1996

[12] Eurocontrol, "Definition of A-SMGCS levels", 2005

[13] A. Chen, "Development of a hybrid deterministic-statistical GPS for airport navigation", 2010 
[14] T. Murphy, G. A. McGraw, M. Brenner, S. Pullen, A.J. Van Dierendonck - Development of the LAAS Accuracy Models - ION GPS 2000

[15] Y. S. Park, S. Pullen - A study of severe multipath errors for the proposed GBAS airport surface movement application - 2010

[16] RTCA - Minimum Aviation System Performance Standard for the Local Area Augmentation System (LAAS) - D0245 - 1998
[17] T. Murphy, M. Harris, P. Geren, T. Pankaskie, B. Clark, J. Burns - More results from the investigation of airborne multipath errors - The International Civil Aviation Organization (ICAO) Navigation Systems Panel (NSP - Montreal - 11-21 May 2005

[18] T. Murphy, R. Friedman, J. Booth, P. Geren, N. Molloy, B. Clark, I. Burns, 'Program for the Investigation of Airborne Multipath Errors, ION NTM 2004 